Vol. 11 (2): 349-354 (2021)

\title{
INDUCED MUTAGENESIS IN PHASEOLUS VULGARIS
}

\author{
Malvina Kodhelaj ${ }^{1 *}$, Arjana Ylli \\ ${ }^{1 *}$ University of Tirana, Faculty of Natural Sciences, Tirana, Albania; \\ ${ }^{2}$ University of Tirana, Department of Biotechnology, Tirana, Albania;
}

*Corresponding Author Malvina Kodhelaj, e-mail: malvinakarcini@yahoo.com;

Received February 2021; Accepted March 2021; Published April 2021;

DOI: https://doi.org/10.31407/ijees11.222

\begin{abstract}
Beans (Phaseolus vulgaris) are considered as one of major leguminous plants and represent a high genetic and important variability for agricultural production. With climatic changes that have occurred in recent years, its production has been significantly reduced. One of the problems was the abortion of flowers of the beans, so the legumes do not survive due to high temperatures and droughts in this period. The use of induced mutagenesis techniques is one of the most important methods for the creation of new varieties. Through induced mutation techniques on bean seeds we tried to extend the time of flowering and to eliminate the abortion of flowers. Besides the economic benefits, induced mutagenesis techniques also play an important role in the study of genetics and plant development. For the realization of this study bean seeds were taken as plant of the family of legumes, and were treated with gamma irradiation of Cz-137, with three doses and chemical mutagen dES also in three doses. The impact of climate changing conditions and temperature stress treated plants have reacted positively being more resistant compare with control plants. Results obtained in the first generation of mutant M1 indicate changes compared to control for the both treatments. Changes have been noted in the amount of Chlorophyll pigments related to the acceleration of flowering, where the first doses of dES has given more and fast flowers compared to the control. There were changes in the maturity period for the two gamma rays doses (100 Gy and $150 \mathrm{~Gy}$ ).
\end{abstract}

Keywords: Chemical mutagen, Gamma irradiation, Phaseolus Vulgaris, Mutation. 